\title{
Willingness to Join and Pay for Social Health Insurance Scheme Among employees in Debere Berhan Town, Ethiopia
}

Wassie Negash Mekonnen ( $\nabla$ wassienegashh@gmail.com )

Debre Berhan University https://orcid.org/0000-0002-0869-9747

\section{Mesfin Wondaferew}

Ethiopian health insurance agency

Adugnaw Birhane Mekonen

Addis Ababa University School of Public Health

Research article

Keywords: Social health insurance, Contingent Valuation ,willingness to pay

Posted Date: October 14th, 2019

DOI: https://doi.org/10.21203/rs.2.15992/v1

License: (1) (i) This work is licensed under a Creative Commons Attribution 4.0 International License.

Read Full License 


\section{Abstract}

Back ground: Social Health Insurance improves access to health services among civil servants by removing catastrophic health expenditure. In Ethiopia, only $7.3 \%$ of the population covered by health insurance. Due to this fact the government of Ethiopia initiated Social Health Insurance scheme to be applied in the formal employers and employees with compulsory membership of the scheme. This study therefore aimed to assess willingness to join and pay for social health insurance scheme among government and private employees in Debere Berhan Town, Ethiopia .

Methods: Cross-sectional study was conducted .At mean time Stratified sampling technique was used to select 619 employees. A modified dichotomous contingent valuation method (CVM) was applied to elicit employees' willingness to pay. Bi-variant and multivariable logistic regression analysis was done. Then the result at $95 \% \mathrm{Cl}$ and $\mathrm{P}$ value $<0.05$ was declared as variables have statistically significant association.

Results: A total of 619 employees with response rate of $97.8 \%$ were participated in the study. About 406 (65\%) of the respondents were willing to join to Social Health Insurance scheme. Of which $113(27.8 \%)$ of employees were willing to pay the government proposed $3 \%$ premium. The employee's average willingness to pay for social health insurance scheme was $1.88 \%$ of their monthly salary. In this study the odds of respondents who had degree and above (AOR=3.608,95\% $\mathrm{Cl} 1.177-11.061)$, employees good perception on quality health service (AOR=3.150, 95\% $\mathrm{Cl} 1.140-8.699)$ and employees who perceive benefit packages of social health insurance as enough (AOR=5.229, 95\% Cl: 2.230-12 .594) were higher than the counter parts.

Conclusion: Employees willingness to join of the Social Health Insurance scheme(SHIS) is low and very low number of employees agree to pay the government proposed premium for SHIS. So decision-makers should emphasize to revise the benefit packages and the premiums to be contributed. likewise insurance agency and all responsible bodies should aware the society about the importance of social health insurance for the employees.

\section{Background}

Every country in the world can aspire to universal health coverage, so as to improve the health and welfare of all their citizens. Since health is a basic right for people, developed counties have served equitable health services for their people and it is free or at lower cost (1).

In Sub-Saharan African countries, the primary source for financing their health care system have been from the government budgets (2). Like other sub-Saharan countries health financing has been a major challenge for Ethiopia. One third of Ethiopian annual health expenditure allocated from donors which is very high. However social health insurance activity is not applied in Ethiopia and the coverage of any form of health insurance is only $7.3 \%$ of the total population (3). 
In order to address this problem and create equitable financing mechanism, the government of Ethiopia is currently undertaking a number of activities to introduce social health insurance (SHI) with the overall objective of achieving universal health access. But there is still on process not yet started (4).It is essential to gather reliable information about the amount that uninsured people are willing to pay for health insurance coverage. Unless agree on this fact application of health insurance is very difficult (5). Studies conducted in different parts of Africa and Asia reported that different socio-demographic and economic factors were responsible for low level of willingness to pay for SHIS. The factors that affect willingness may vary from person to person, country to country due to different reasons $(6,7)$.

Studies showed that, the greatest proportion of workers in the public sector were not willing to join SHI. The reason for government employee not willing to join is that the salaries in the public sector are very $\operatorname{low}(8)$.

Study conducted in Addis Ababa Ethiopia showed that, in spite of the appreciation of the initiation of social health insurance, the majority of employees from public enterprises and civil service organizations were not happy about making contributions for the scheme. At mean time Respondent's stated that low salary scale, increasing of cost of living and other regular expense were limited their contribution to SHI(9).

In Ethiopia context, social health insurance program is new for majority of the community and the employees. There is no adequate information about health insurance concept, principles and benefits among employees and employers. Due to this fact beginning of $\mathrm{SHI}$ is a challenge for the government. Because the government Ethiopia is unclear on the employees willingness to join to SHI,the amount the members willing to pay and the benefit packages the insurance companies should consider. Hence before expansion of health insurance employee should understand advantages, benefit packages, challenges and the employees willingness to pay for social health insurance. So this study aimed to asses that employees' willingness to join to SHIs.At mean time this study aimed to asses employees ability and commitment to pay the premium for SHls. This study also provided information to health policy makers and implementers about factors affecting implementation of social health insurance and willingness of the employee to join and pay for SHI.

\section{Objectives}

\section{General objective}

To assess willingness to join and pay for social health insurance scheme among employees in Debere Berhan Town, Ethiopia, 2018.

\section{Specific Objectives}

To assess willingness of employees to join for social health insurance scheme. 
To assess willingness of employees to make compulsory monthly contributions for social health insurance.

Identify the factors affecting employees' willingness to contribute to social health insurance scheme.

\section{Methods}

A cross-sectional study was conducted from August 1 to September 30, 2018 in Debere Berhan Town which is one of the ancient towns of Ethiopia. It is estimated to have greater than 600 years age and it is located in central part of the country. Debre Berhan Town is located $130 \mathrm{kms}$ North east of Addis Ababa. Its altitude is about 2500-2800 meters above sea level. It is known in Ethiopia with cooled climatic condition average daily temperature is $12.6^{\circ} \mathrm{C}$. The total population of the town based on 2017 censuses data were 97,969. There were 81 Government sectors which include Federal, Regional Zonal District sectors with a total of 6851 employees $(33,34)$. There were also 278 private sectors with 3159 private employee.

The source population was all employees who were working in government and private formal sectors in Debere Berhan Town. The sample size was determined by using single population proportion formula. By considering Proportion of employees who were willing to pay for $\mathrm{SHI}=50 \%(\mathrm{p}=0.5)$ from previous study. And $95 \%$ confidence interval $(Z=1.96)$, and margin of error $(d=0.05)$. The calculated sample size was 384 ; and adding $10 \%$ for potential non-response, and multiplying by a design effect of 1.5 and the final sample size became 633.

A stratified sampling technique was used to select study participants. Stratification were done based on ownership of sectors as Government and private. The total samples were proportionally allocated to each of the stratum based on the number of employee in each stratum. The sampling frame for each stratum was the list of employee in the organization, and samples were selected from each stratum using simple random sampling technique. A modified dichotomous (type of contingent valuation method (CVM) choice format was applied to elicit employees' willingness to pay. To maintain the quality of data questionnaire was prepared in English and translated into local language Amharic and back translated into English to check for consistency. Pretest was also done on $5 \%$ of the sample size in near bay town.

The Data were collected using structured questionnaire adapted from different studies (10-11) and modified to fit the local context. A data collection team consist of 9 personnel (the principal investigator, 6 data collectors and 2 supervisors) was established and recruited. Data collectors were trained for 2 days on techniques of data collection and management. Data's was entered and cleaned in to EPI INFO version 7 software programs and finally analyzed using SPSS version 16 software package. Description of the study population was done by analyzing the distribution of the respondents by the variables in terms of frequencies and percentage. Bi-variable logistic regression analysis were carried out to determine the associations of selected independent variables with dependent variables. Variables with P-value of less than or equal to 0.25 was taken as a cut-off point for candidate variables for the final multivariable 
logistic regression models. Independent predictors were determined using odds ratio at $95 \%$ confidence interval. And variables at $p$-value less than 0.05 were declared as statistically significant.

At mean time the ethical issues were considered by getting ethical clearance from Ethical review board of college of health sciences Debre Berhan University. Official permission was obtained from selected Government and private organization and informed consent was obtained from individual participants as well.

\section{Results}

\section{Socio-demographic characteristics of the employees}

A total of 619 employees were participated in the study from 9 Government and private sectors which makes response rate $97.8 \%$. More than half $389(62.8 \%)$ of respondents were males. And the median age of the respondents were 33 with standard deviation + (SD) 8.8 years old. Three hundred thirty $(53.3 \%)$ of respondents were not married. Regarding educational status $352(56.9 \%)$ of them had diploma and below, while 267 (43.1\%) of the respondents' had first degree and above. Four hundred four $(71.7 \%)$ of employee in the study area, have more than four family size. About $225(36.3 \%)$ of respondents earn salary of greater than 3501 Ethiopian Birr (ETB), (Table.1).

\section{Social Health Insurance Scheme and their sources of information}

Five hundred eighty five (94\%) of the respondents were heard about proposed social health insurance scheme through different types of medias. Television and radio was their main source of information.

About 229 (37\%) of the employees heared about social health insurance. Whereas majority of the respondents $390(63 \%)$ did not heard about risk pooling ability of social health insurance

\section{Health Status and Health Care utilization of Employees}

In this study, about $315(50.9 \%)$ of the respondents had at least one family members with history of illness in the past 1 year. Among this 65 (20.6\%) of them had history of chronic illness. At mean time 107 (40\%) of the respondents who had an experience of illness were found to seek medical care from public health facility, while $165(60 \%)$ sought from private health facility.

\section{Institutional related factors}

About 453 (73\%) employee's perceived quality of health care at government sectors to be generally poor and the rest side that quality is good. While $485(78 \%)$ of respondents said that quality of care at private health facility was good. Similarly about $175(28 \%)$, employees perceived drugs are available most of the time at government health facility. whereas majority 417 (67.4\%) of respondents agreed that drugs are 
most of the time available at private health facility. And also respondents replied about their perception of waiting time for medical care as short were $112(18 \%)$ and $418(67.5 \%)$ in government and private health facility respectively.

\section{Exposure and perception of employees about the elements of social health insurance scheme}

Regarding the benefit package of SHI 462 (74.6\%) of the respondents did not perceived the benefit package of SHI scheme was enough. Only $57(25.4 \%)$ of them perceived the benefit package of SHI scheme was enough. About $519(84 \%)$ of the respondents perceived the premium should pay by either husband or wife, Whereas $100(16 \%)$ of individuals perceived both of them should pay at the same time.

\section{Willingness to join and pay of employees for social health insurance scheme}

A total of 406 (65\%) of the employees were willing to join the proposed social health insurance scheme of these 351 (82.7\%) were from government sector and 55 (28.2\%) from private sector. Whereas 213 (35\%) of the respondents were not willing to join the proposed social health insurance scheme. Their main reason for not willing to pay were poor implementation and poor quality of services within the organization (Table 2).

Out of the 406 employees who were willing to join the proposed social health insurance scheme 113 $(27.8 \%)$ were willing to pay the proposed $3 \%$ of their salary and out of this $100(88.5 \%)$ and $13(14.5 \%)$ were from government and private sector respectively, (Table 3).

\section{Predictors for willingness to pay for social health insurance scheme}

Independent variables were entered in stepwise multivariable logistic regression to control potential confounder variables. As a result employees who had more than 4 families were $94 \%$ less likely willing to pay(WTP) for SHIS compared to those who had 4 and leas family members (AOR $=.060,95 \% \mathrm{Cl} .023$ -.157). Similarly married were $92 \%$ less likely WTP for SHIS than not married (AOR $=.084,95 \% \mathrm{Cl} . .028$ -.254). Employees who had degree and above were 3 times more likely willing to pay than who had diploma and below (AOR $=3.608,95 \% \mathrm{Cl} 1.177-11.061)$. It also found that respondents who earned more than 3501 ETB were 8 times more likely WTP for SHIS than those who earned less than 1500 ETB (AOR; $8.690,95 \% \mathrm{Cl}(1.446-52.219)$. Those who perceived good quality of health service were 3 times more WTP for SHIS compared to who did not perceived good quality of health service in government health facility (AOR; $3.150,95 \% \mathrm{Cl}(1.140-8.699)$. Employees who perceived always availability of drugs at health facility were 8 times more WTP for SHIS than who perceived not available (AOR; $8.127,95 \% \mathrm{Cl}$ (3.094-21.342). Respondents who had history of illness in their family in the past 1 year were 3 times more likely WTP for SHIS compared to who had not (AOR; 3.728, $95 \% \mathrm{Cl}(1.451-9.578)$. And also those 
respondents who had chronic illness were 3 times more WTP for SHIS than who had not (AOR; 3.024, $95 \% \mathrm{Cl} 1.067-8.571)$. Individuals who respond the benefit package of $\mathrm{SHI}$ is enough were 5 times more likely willing to pay than who perceived the benefit package as not enough (AOR; $5.299,95 \% \mathrm{Cl} 2.230$ 12.594). And also those employees who perceived the beneficiary of SHIS is enough were 3 times more likely WTP for SHIS compared to respondents who perceived the beneficiary of SHI is not enough (AOR = $3.264,95 \% \mathrm{Cl} 1.303-8.179)$. It was also found that respondents who thought employees who were husband and wife should pay for health insurance at the same time were $83 \%$ less likely WTP for SHIS than who thought one of them should pay for the scheme (AOR $=.170,95 \% \mathrm{Cl} 043-2.675)$ (Table, 4).

\section{Discussion}

The results of this study indicate that $65 \%$ of the employees were willing to join the proposed SHIS. This is lower than study conducted in Nigeria, and Addis Ababa which was $83 \%$ and $90 \%$ respectively $(12,13)$. But it is higher than a study done in south India where only $39 \%$ were willing to join (14). From this study, among those individuals who were willing to join SHIS only $27.8 \%$ were willing to pay the proposed $3 \%$ of their monthly salary, the remaining $72.2 \%$ the respondent were willing to pay less than $3 \%$ of their monthly salary. This result is two times lower than the study conducted in Wolaita Sodo (Ethiopia) where $74.4 \%$ of the respondents willing to pay $3 \%$. But it is greater than study conducted in Addis Ababa(Ethiopia) St. Paul's hospital: only $17 \%$ health of workers were willing to pay $3 \%$ of their monthly salary. The difference could be due to less promotional efforts being taken by health insurance agency to the study area and also some employees may consider their health insurances should be covered by their employer's $(15,16)$.

The average willingness to pay of the respondent for social health insurance is 56.40 ETB (US\$2.08) per month which is $1.88 \%$ of their monthly. Their WTP per person per year reached 676.80 ETB (US\$25.06). This is almost similar with study done in Addis Ababa which was about 57.94 ETB per month. And also lower than study conducted in Wolaita (Ethiopia) which was 81.66 ETB (US\$ 3.02) per month. The rate of premium willingness to pay is greater than with another study conducted in Addis Ababa and Iran which revealed that $1.58 \%$ and $1.39 \%$ of their monthly salary respectively. And little bit lower than study conducted in Namibia which reported as $2 \%$ of their monthly salary per month. The disparity might be related to the difference in cost of living conditions and their perception of being at risk of illness $(13,16$, $17,18, \& 19)$.

The other objective of this study was identifying the determinants of willingness to pay for health insurance. Respondents who had $>4$ family's members were $94 \%$ less likely WTP for SHIS than those with $<4$ family's (AOR; $0.060,95 \% \mathrm{Cl}(.023-.157)$. This result indicates family size has a negative impact on employee's willingness to pay. This might be because the higher the family size, the lesser per capita income and may prioritize other expenditure rather than health insurance that means a large family with lower income may affect their willingness to pay. This result is supported by the study done in Iran and Adama (Ethiopia) where people who had large family size did not want to pay $(18,20)$. But it is 
inconsistent with study conducted in Nigeria where family size has positive relation (21). This disparity might be due to beneficiary stated in the Ethiopian SHI proclamation 690/2010.

Marital status was another factor associated with WTP for SHIS of respondents. Those married respondents were $91.6 \%$ less likely willing to pay as compared to unmarried (AOR;.084 95\%Cl.028-.254). Three explanations might be given for this result. First, married employees are less willing to pay due to high expenses they face related to their families over the 'unmarried 'employees. Second, those respondents who were married and both of them were employees might not agree to contribute the premium at the same time even though the proclamation stated any employees should pay to the scheme. But unmarried ones contribute for the scheme is only he/she, therefore they will be more willing to pay than married ones. Third unmarried employees have more income disposable than married employees thus they are more willing to pay. In other words it shows effect of family income. This study is in line where study conducted in Wolaita(Ethiopia) but inconsistent with study conducted in India (16). Educational status is positively associated with employees willingness to pay; respondents who had first degree and above were 3.6 times more likely WTP for SHIS than those respondents who had diploma and below (AOR; 3.608, 95\% Cl 1.177-11.061). This means that more educated employee would be willing to contribute the premium. This finding is consistent with a study done in (Iran, Namibia, and Addis Ababa) where, those with higher level of education willing to pay for National Health Insurance Scheme $(13,18$, 19$,$) . This might be due to more educated employee were easily adopt new program and they can have an$ access and utilize information easily than less educated ones. And also those with high educational level \& high monthly income might be a reason to prefer SHI because they can easily contribute.

An employee's monthly salary positively associated with WTP for social health insurance scheme, respondents with salary of more than 3500ETB were 8 times more likely willing to pay for SHI than those with monthly salary was less than 1500ETB (AOR; 8.690, 95\% Cl 1.446-52.219). It implies that the high income the more willing to pay for the proposed premium. This agrees with a study done in china, Iran, India, Namibia, and Addis Ababa where respondents with higher income were more willing to pay for health insurance than those with lower income $(7,13,1418,19$,and 22$)$. This may be comparatively those with the higher income can have an ability to afford the premium easily and it promotes one of the principles of health insurance known as risk pooling. On the other hand respondents with less income may prioritize other expenditure rather than health insurance.

Employees and their families who experienced illness in the last twelve month were found another important factor for willingness to pay of the premiums of SHIS. Respondents whose family was experienced any type of illness in last 12 months before interview were 3 times more willing to pay than those who were not experienced any illness in the past one year (AOR; 3.024, 95\% Cl (1.067-8.571). This result is consistent that was found in Cameron, Efratana Gedem district and Adama (Ethiopia) $(20,23$, 24). However, such kind of preference of social health insurance leads to an adverse selection which is one of the major challenges of health insurance. Because if there is imbalance of enrolment between sick and healthy members, frequent visit of health facility by chronic patient increases that leads to high claim for the scheme. And it could be challenge for financial sustainability of the social health insurance 
scheme. Employees who perceived good quality of health service at health facility were 3 times more willing to pay for the scheme compared to who did not perceived good quality of health service (AOR = 3.150, 95\%Cl:1.140-8.699). Similarly, study done in, Addis Ababa and kewet and Efratana Gedem district (Ethiopia) showed that quality of health service were one of the most significant factor for WTP for SHIS $(9,24)$. This indicates that improve the quality of health services might leads to increase the willingness to pay of an employees.

Availability of drugs was another factor associated with WTP for SHIS of respondents. Respondents who perceived the prescribed drugs were always available at health facility were 8 times more likely to willing to pay compared to who did not perceived always is available (AOR $=8.127,95 \% \mathrm{Cl}: 3.094-21.342)$. This result is in line with qualitative research on knowledge and preference of health insurance that was done in Addis Ababa where service availability (drugs, investigations, physicians) can affect the willingness to pay (9). This is in fact that one's people insured they want to be secured for drug availability because they do not want to practice out of pocket expenditure for medical services. They already pre-paid for the service therefore they will not want to expose to extra expenditure (to buy drugs and other medical services).

Similarly respondents who thought the benefit packages is enough were 5 times more willing to pay than who perceived it is not as enough ( $\mathrm{AOR}=5.229,95 \% \mathrm{Cl}: 2.230-12.594)$. This is in line with study done in Addis Ababa where most focus group discussants agreed comprehensiveness of benefit packages found to be limited and affect their willingness to pay. And also the result is supported study conducted in Ghana where members of health insurance were satisfied with the benefit package and they were eager to renew their membership $(9,25)$.

Furthermore, employees who perceived the beneficiary of SHIS is enough were 3times more likely WTP for SHIS than respondents who perceived the proposed beneficiary of $\mathrm{SHI}$ is not enough (AOR $=3.264$, $95 \% \mathrm{Cl} 1.303-8.179$ ). Similarly a qualitative study done in Addis Ababa shows that the respondents dissatisfied with the current proposed beneficiary and that can be a cause for less willingness to pay for SHIS. And they perceived many dependents are in their families which are out of list of beneficiary in the proclamation of SHI. They may want to add extra families beyond the stated in the proclamation. Therefore respondents stated that proposed beneficiary of SHIS should be updated (9). Because extended family is common in Ethiopia and they consider ignored the type of strong social attachment between families and also they consider their family income. Where larger family members exclude out of the scheme, the family members may expose to financial shortage when they seek health care.

\section{Limitation of the study}

It included only monthly salary of the employee as monthly income. Another source of income of the respondents not assessed.

\section{Conclusions}


Employees willingness to join of the SHI scheme is low.And very low number of employees agree to pay the government proposed premium for SHIS.

Employee's willingness to pay for the scheme is positively related with study variables such as educational status, monthly salary, any illness experience in the family, presence of chronic illness, employees' perceptions on quality of health service, availability of drugs in health facility, perceived benefit package and perceived beneficiary of SHIS, whereas marital status, family size and perceived premium base of $\mathrm{SHI}$ are negatively related. These variable were found significantly determine the employees willingness to pay for social health insurance.

\section{RECOOMONDATION}

The Ethiopian Social Health Insurance Agency should adequately enhance and intensify employees awareness creation especially about the principles and benefit packages of social health insurance. And the premium could be consider the employees ability and willingness to pay. At mean time health sector organizations need to improve the quality of services and try to make available all of the necessary drugs and services. In doing so the regional health bureau, health insurance agency and local health sector organizations do in collaboration to enhance their awareness about SHIS.

\section{Abbreviations}

AOR Adjusted Odd Ratio

$\mathrm{CBHI}$ Community Based Health Insurance

$\mathrm{Cl}$ Confidence Interval

CVM Contingent Valuation Methodology

DBU Debere Berhan University

EHIA Ethiopian Health Insurance Agency

EFDR Ethiopia Federal Democratic Republic

ERB Ethical Review Board

ETB Ethiopian Birr

$\mathrm{MOH}$ Ministry of Health

NGO Non-Government Organization

NHIS National Health Insurance System 
PHC Primary Health Care

POESSA Private Organization Employee Social Security Agency

SHIS Social Health Insurance Scheme

SPSS Statistical Package for the Social Sciences

SSA Social Security Agency

UHC Universal Health Coverage

WHO World Health Organization

WTJ Willingness to Join

WTP Willingness to Pay

\section{Declarations}

\section{Ethics approval and consent to participate}

Ethical approval was obtained from the Debre Berhan University Research Ethics Review Committee and informed oral consent was taken from every study participants

\section{CONSENT FOR PUBLICATION}

Not applicable

\section{Availability of data and materials}

Data are available from authors on reasonable requests.

\section{Competing interests:}

The authors declare that they have no competing interests Data are available from authors on reasonable requests.

\section{Funding}

No funding 


\section{Authors' contributions}

$M W, A B$ and $W N$ has made substantial contributions to conception and design the protocol; MW performed data collection and analysis and interpretation of the findings and wrote paper; $A B, W N$ have been involved in guiding data analysis and report writing. At mean time $A B, W N$ drafting the manuscript edited and finalize the manuscript; $M W, A B$ and $W N$ have given final approval of the version to be published; and agree to be accountable for all aspects of the work in ensuring that questions related to the accuracy or integrity of any part of the work are appropriately investigated and resolved.

\section{Acknowledgments}

We thank Debere Berhan University for giving ethical approval of this study. We would like to acknowledge all study participants for their willingness to provide the necessary information.

\section{References}

1. Akiko M, Edson A, Cheryl C, Joseph H, Universal Health Coverage for Inclusive and Sustainable Development. A Synthesis of 11 Country Case Studies: The World Bank Washington DC, 2014.

2. Ethiopian Public Health Institute; An Evidence-Based Policy Brief improving health care financing in Ethiopia. August 2014.www.portal.pmnch.org/evidence/.../es improving health care finance...pdf.

3. Federal Democratic Republic of Ethiopia Ministry of Health, Health Sector Development Program 2010/11-2014/15, Ministry of health Ethiopia 2010;33-7.

4. Federal Democratic Republic Of Ethiopia Proclamation No. 690/2010 Social Health Insurance Proclamation Page 5494, Addis Abeba, 2010. www.ilo.org/.../Social\%20Health\%20Insurance\%20Proclamation\%...pdf.

5. The willingness-to-pay concept in question. Rev Saudi Pública 2009; 43www.scielo.br/pdf/rsp/v43n2/en_7156.pdf

6. .Lisa O, Michael S, Aurelia S, German S Community-based Health Insurance and Household Welfare -Empirical Evidence from Burkina Faso, April 2014.

7. Barnighausen $T$, Liu Y, Zhang $X$ and Sauerborn R. Willingness to pay for social health insurance among informal sector workers in Wuhan, China: a contingent valuation study. BMC Health Services Research 2007;

7:114.https://www.google.combmchealthservres.biomedcentral.com/articles/10.1186/1472-69637-114.pdf

8. Asgary A, Willis K, Taghvaei A.A, and Rafeian M; Estimate rural households' willingness to pay for health insurance. Eur J Health Econom, 5:209-215, 2004.. https://www.ncbi.nlm.nih.gov/pubmed/15714341.pdf.

9. Amarech $\mathrm{O}$, Damen $\mathrm{H}$. and Charles $\mathrm{N}$, knowledge and preference for health insurance demands among formal sector employee in Addis Abeba town, Obse et al. BMC Health Services Research 
(2015) 15:318, DOI 10.1186/s12913-015-0988-8.

https://wwwbmchealthservres.biomedcentral.com/articles/10.1186/s12913-015-0988-8.pdf.

10. Ethiopian Health Insurance Agency special published magazine, Vol. 1 No, 1, Addis Ababa June, 2015.

11. Shimeles O, Berhan M, Questionnaire for A Study on Willingness to Join and Pay For CBHI Among Households in Rural Areas of Debub Bench District, Bench Magi Zone, Southwest Ethiopia, 2013.

12. Obinna $\mathrm{O}$. and Edit $\mathrm{V}$. Willingness to pay for private voluntary health insurance in southeast Nigeria, African Journal of Health Economics xxx 2012 xxx.

www.ajhe.org/Onwujekwe_Velenyi_Revised11.25.2008FINAL.pdf

13. Yared $W$. H, Preference for health care financing options and willingness to pay for compulsory health insurance among government employees in Ethiopia, Umea International School of Public Health, Umea University, Sweden,2009. www.phmed.umu.se/digitalAssets/30/30117_2009-21yared-woldemariam.pdf

14. Bhagirathi $R$, Awareness, attitude and their correlates towards health insurance in an urban south Indian population Management in health XVI/1/2012; pp. 3235.journal.managementinhealth.com/index.php/rms/article/view/221/658.pdf.

15. Yared L, Yeshwondm M, Semira A, Willingness to Pay for the Newly Proposed Social Health Insurance among Health Workers at St. Paul's Hospital Millennium Medical College, Addis Ababa, Ethiopia. International Journal of Health Economics and Policy, Vol. 2, No. 4, 2017, pp. 159-166. Doi: 10.11648/j.hep.20170204.13

16. Tesfamichael AA, Mirkuzie W, Shimeles 0 . Willingness to pay for a newly proposed social health insurance among teachers in Wolaita Sodo town, South Ethiopia. Ethiop J Health Sci (2014) 24(3):195-202. Doi: 10.4314/ ejhs. v24i3.2https://www.ncbi.nlm.nih.gov > NCBI > Literature > PubMed Central (PMC)

17. Amarech G O, 'Health insurance demand among formal sector employees in Addis Ababa, Ethiopia', [thesis], Trinity College (Dublin, Ireland). Department of Public Health and Primary Care, 2014, pp. 242.

18. Shirin N, Arash R, Mohsen M, Ali AS, Ghadir M\& Maryam M,Willingness To Pay for Social Health Insurance in Iran, School of Public Health and Knowledge Utilization Research Center, Tehran University of Medical Sciences, Tehran, Iran,2014, (P61)https://www.ncbi.nlm.nih.gov/pmc/articles/PMC4825503/.pdf.

19. . Emily G. and Abay A. Willingness to pay for health insurance: An analysis of the potential Market for new low- cost health insurance products, Namibia, September, 2009. www.sciencedirect.com/science/journal/02779536/69/9.pdf

20. Birku RE, Nnaemeka VE, Health Insurance Technology in Ethiopia: Willingness to Pay and Its Implication for Health Care Financing, Adama,2016, Vol. 4, No. 3, 98- 106 http://pubs.sciepub.com/ajphr/4/3/4 
21. Dr. Usman, A, Willingness to Pay For Community Based Health Care Financing Scheme; A Comparative Study among Rural and Urban Households in Osun State,Nigeria, Nigeria, Mar, - Apr. 2013.

22. Dr. Sumninder KB, Awareness and Willingness to Pay for Health Insurance: An Empirical Study with Reference to Punjab India, Vol. 1 No. 7 [Special Issue - June 2011]

23. . Hermann Pythagore Pierre Donfouet, Social Capital and Willingness-to-Pay for Community-Based Health Insurance in Rural Cameroon, Vol. 3, No. 1; April 2011.

24. Eshetu M, Households' Willingness to Pay for Community Based Health Insurance Scheme: in Kewet and Efratana Gedem Districts of Amhara Region, Ethiopia, 2017, Vol. 7, No. 2.

25. D. Adei, E. Amankwah and I. Sarfo Mireku, An Assessment of the National Health Insurance Scheme in the Sekyere South District, Ghana, Current Research Journal of Social Sciences 7(3): 67-80, 2015

\section{Tables}

Table 1: Socio-demographics characteristics of respondents in Debere Berhan Town, Ethiopia 2018, $(\mathrm{N}=619)$. 


\begin{tabular}{|c|c|c|c|}
\hline Variable & & Frequency $(n=619)$ & Percentage (\%) \\
\hline \multicolumn{4}{|c|}{ Sex of the respondent } \\
\hline & Male & 389 & 62.8 \\
\hline & Female & 230 & 37.2 \\
\hline \multicolumn{4}{|l|}{ Age } \\
\hline & $18-30$ & 283 & 45.7 \\
\hline & $31-40$ & 203 & 32.8 \\
\hline & $41-50$ & 117 & 18.9 \\
\hline & $51 \&$ above & 16 & 2.6 \\
\hline \multicolumn{4}{|l|}{ Marital status } \\
\hline & Married & 278 & 44.9 \\
\hline & Not married & 330 & 53.3 \\
\hline & Divorced & 7 & 1.1 \\
\hline & Widowed & 4 & 0.6 \\
\hline \multicolumn{4}{|c|}{ Educational status } \\
\hline & Primary school & 31 & 5 \\
\hline & Secondary school & 90 & 14.5 \\
\hline & Diploma & 231 & 37.3 \\
\hline & $1^{\text {St }}$ Degree $\&$ above & 267 & 43.1 \\
\hline \multicolumn{4}{|l|}{ Family size } \\
\hline & $\leq 4$ & 175 & 28.3 \\
\hline & $>4$ & 444 & 71.7 \\
\hline \multicolumn{4}{|l|}{ Salary in birr } \\
\hline & $\leq 1500$ & 128 & 20.7 \\
\hline & $1501-2500$ & 85 & 13.7 \\
\hline & $2501-3500$ & 181 & 29.2 \\
\hline & $\geq 3501$ & 225 & 36.3 \\
\hline
\end{tabular}

Table 2:Reason for not willing to join the Social Health Insurance Scheme, among government and private employees Debre Berhan Town, Ethiopia, 2018 ( $n=213)$.

\begin{tabular}{|l|l|l|}
\hline Reasons not willing to join the scheme & Number & Percent \\
\hline Always I am in good health & 19 & 8.8 \\
\hline I do not have enough money & 24 & 11.2 \\
\hline I do not believe well implementation /poor implementation & 66 & 30.7 \\
\hline I do not believe to get quality health service & 53 & 24.7 \\
\hline Scopes of illnesses covered by the scheme is limited & 53 & 24.7 \\
\hline Total & 213 & 100 \\
\hline
\end{tabular}


Table 3: Employees Willingness to join and pay for social health insurance scheme among government and private employees Debre Berhan Town, Ethiopia, 2018.

\begin{tabular}{|l|l|c|c|c|c|c|c|}
\hline \multirow{2}{*}{ Variables } & \multirow{2}{*}{ Response } & \multicolumn{2}{|c|}{$\begin{array}{c}\text { Government } \\
\text { sector }\end{array}$} & \multicolumn{2}{c|}{ Private sector } & \multicolumn{2}{c|}{ Total } \\
\cline { 3 - 8 } & & Frequency & $\%$ & Frequency & $\%$ & Frequency & $\%$ \\
\hline \multirow{2}{*}{$\begin{array}{l}\text { Willingness to join } \\
\text { to SHI }\end{array}$} & Yes & 351 & 82.7 & 55 & 28.2 & 406 & 65 \\
\cline { 2 - 8 } & No & 73 & 17.3 & 140 & 71.8 & 213 & 35 \\
\hline \multicolumn{2}{|c|}{ Total } & 424 & 100 & 195 & 100 & 619 & 100 \\
\hline $\begin{array}{l}\text { Willingness to pay } \\
\begin{array}{l}3 \% \\
\text { premium salary for }\end{array}\end{array}$ & Yes & 100 & 28.4 & 13 & 23.6 & 113 & 27.8 \\
\cline { 2 - 8 } & No & 251 & 71.6 & 42 & 76.4 & 293 & 72.2 \\
\hline \multicolumn{2}{|c|}{ Total } & 351 & 100 & 55 & 100 & 406 & 100 \\
\hline
\end{tabular}

Table4; Determinant of WTP for the proposed SHI among employees in Debre Braham Town, Ethiopia, in $2018(\mathrm{~N}=406)$. 


\begin{tabular}{|c|c|c|c|c|c|c|}
\hline \multirow{2}{*}{\multicolumn{3}{|c|}{ Variables }} & \multicolumn{2}{|c|}{ WTP 3\% } & \multirow{2}{*}{$\begin{array}{l}\text { COR (95\% } \\
\text { CI) }\end{array}$} & \multirow[b]{2}{*}{ CI) ${ }^{\text {AOR }(95 \%}$} \\
\hline & & & Yes & No & & \\
\hline \multirow[t]{2}{*}{ Family size } & \multirow{2}{*}{\multicolumn{2}{|c|}{$\begin{array}{r}>4 \\
<=4\end{array}$}} & 36 & 244 & $\begin{array}{l}.094 \\
(.057-.155) *\end{array}$ & $.060(.023-.157)$ \\
\hline & & & 77 & 49 & 1 & 1 \\
\hline \multirow[t]{3}{*}{ Marital status } & \multirow{2}{*}{\multicolumn{2}{|c|}{$\begin{array}{l}\text { Never married } \\
\text { Married }\end{array}$}} & 72 & 151 & 1 & 1 \\
\hline & & & 37 & 137 & $\begin{array}{l}.556 \\
(.358-.896) *\end{array}$ & $\begin{array}{l}.084 \\
-.254) * *\end{array}$ \\
\hline & \multicolumn{2}{|c|}{ Others } & 4 & 5 & $\begin{array}{l}1.678(.215- \\
5.228)\end{array}$ & $\begin{array}{l}2.998(.200- \\
44.886)\end{array}$ \\
\hline \multirow[t]{2}{*}{ Educational status } & \multicolumn{2}{|c|}{$\begin{array}{l}\text { First degree and } \\
\text { above }\end{array}$} & \multirow[t]{2}{*}{92} & 116 & $\begin{array}{l}6.685 \\
(3.940- \\
11.342) *\end{array}$ & $\begin{array}{l}3.608(1.177- \\
11.061)^{*}\end{array}$ \\
\hline & \multicolumn{2}{|c|}{ Diploma \& below } & & 177 & 1 & 1 \\
\hline \multirow[t]{4}{*}{ Salary } & \multicolumn{2}{|c|}{$<=1500$} & \multicolumn{2}{|r|}{75} & 1 & 1 \\
\hline & \multicolumn{2}{|c|}{$1501-2500$} & 4 & 44 & $\begin{array}{l}.974(.270- \\
3.516)\end{array}$ & $\begin{array}{l}1.327(.184- \\
9.560)\end{array}$ \\
\hline & \multicolumn{2}{|c|}{$2501-3500$} & 31 & 97 & $\begin{array}{l}3.424 \\
(1.429- \\
8.204)\end{array}$ & $\begin{array}{ll}4.735 & (.943- \\
23.775)\end{array}$ \\
\hline & \multicolumn{2}{|c|}{$>3501$} & 71 & 77 & $\begin{array}{l}9.879 \\
(4.269- \\
22.882) *\end{array}$ & $\begin{array}{l}8.690 *(1.446- \\
52.219) *\end{array}$ \\
\hline \multirow[t]{2}{*}{$\begin{array}{l}\text { Perceived quality of health } \\
\text { Service }\end{array}$} & & $\begin{array}{l}\text { At least } \\
\text { good }\end{array}$ & \multicolumn{2}{|c|}{\begin{tabular}{l|l}
4 & 79
\end{tabular}} & $\begin{array}{l}5.140 \\
(3.226- \\
8.189) *\end{array}$ & $\begin{array}{l}3.150(1.140- \\
8.699) *\end{array}$ \\
\hline & & Poor & 39 & 214 & 1 & 1 \\
\hline \multirow{2}{*}{\multicolumn{2}{|c|}{$\begin{array}{l}\text { Perceived availability } \\
\text { of drugs at health facility }\end{array}$}} & Available & 75 & 67 & $\begin{array}{l}6.658(4.136- \\
10.717) *\end{array}$ & $\begin{array}{l}8.127(3.094- \\
21.342) * *\end{array}$ \\
\hline & & $\begin{array}{l}\text { Not } \\
\text { Available }\end{array}$ & 38 & 226 & 1 & 1 \\
\hline \multirow{2}{*}{\multicolumn{2}{|c|}{$\begin{array}{l}\text { History of illness in the } \\
\text { past } 1 \text { year }\end{array}$}} & Yes & 97 & 130 & $\begin{array}{l}7.601 \\
(4.269- \\
13.534) *\end{array}$ & $\begin{array}{l}3.728(1.451- \\
9.578) *\end{array}$ \\
\hline & & No & 16 & \begin{tabular}{l|l}
163 \\
\end{tabular} & 1 & 1 \\
\hline \multirow{2}{*}{\multicolumn{2}{|c|}{$\begin{array}{l}\text { One of } \\
\text { the household member had } \\
\text { Chronic illness }\end{array}$}} & Yes & 44 & 19 & $\begin{array}{l}9.196(5.056 \\
-16.745) *\end{array}$ & $\begin{array}{l}3.024(1.067- \\
8.571) *\end{array}$ \\
\hline & & No & 69 & 274 & 1 & 1 \\
\hline $\begin{array}{l}\text { Perceive benefit Packag } \\
\text { are enough }\end{array}$ & ges & Yes & 64 & \begin{tabular}{l|l}
59 \\
\end{tabular} & $\begin{array}{l}5.180(3.241 \\
-8.280) * \\
\end{array}$ & $\begin{array}{l}5.299(2.230 \\
-12.594) * * \\
\end{array}$ \\
\hline & & No & 49 & 234 & 1 & 1 \\
\hline $\begin{array}{l}\text { Perceived beneficiaries } \\
\text { of SHI / proposed }\end{array}$ & & yes & 37 & 58 & $\begin{array}{l}1.973(1.212 \\
-3.209) *\end{array}$ & $\begin{array}{l}3.264(1.303- \\
8.179) *\end{array}$ \\
\hline $\begin{array}{l}\text { beneflclaries for SHI is } \\
\text { enough }\end{array}$ & & No & 76 & 235 & 1 & 1 \\
\hline $\begin{array}{l}\text { Who should pay for healt } \\
\text { insurance for married } \\
\text { couple }\end{array}$ & & Both & 9 & 50 & $\begin{array}{l}.421 \\
(.199-. .887) \\
*\end{array}$ & $\begin{array}{l}170(.043-.672) \\
*\end{array}$ \\
\hline & & One of them & 104 & 243 & 1 & 1 \\
\hline
\end{tabular}


** statistically significant at P- Value $<=0.01$, and $*<=0.05$ 